\title{
Evaluation of the referral system in Iran's rural family physician program; a study of Jiroft University of Medical Sciences
}

Reza Dehnavieh ${ }^{1}$, Ehsan Movahed ${ }^{2}$, Hamed Rahimi ${ }^{3}$, Morad Ali Zareipour ${ }^{4}$, Kheir Mohamad Jadgal ${ }^{2}$, Somayeh Alizadeh $^{2}$, Rabea Agh Atabay ${ }^{2}$, Ahmad Haghiri Dehbarez $^{5}$

${ }^{1}$ Ph.D. of Health Care Management, Associate Professor, Health Services Management Research Center, Institute for Futures Studies in Health, Kerman University of Medical Sciences, Kerman, Iran

${ }^{2} \mathrm{Ph}$.D. Student of Health Education and Health Promotion, School of Public Health, Shahid Sadoughi University of Medical Sciences, Yazd, Iran

${ }^{3} \mathrm{Ph} . \mathrm{D}$. Student of Health Care Management, Health Services Management Research Center, Institute for Futures Studies in Health, Kerman University of Medical Sciences, Kerman, Iran

${ }^{4}$ Ph.D. Student of Health Education and Promotion, Urmia City Health Center, Urmia University of Medical Sciences, Urmia, Iran

${ }^{5}$ MPH, Truma and Emergency Medicine Research Center, Hormozgan University of Medical Sciences, Bandar-eAbbas, Iran

\section{Type of article: Original}

\begin{abstract}
Background and objective: Referral systems are relatively easy in terms of design, but implementing them is extremely difficult. Considering the three levels of primary healthcare, access of people to specialized services through a referral system is possible. With regard to the importance of a referral system in a family physician program, this study was performed to assess the function of the referral system in the family physician program in Jiroft University of Medical Sciences.

Methods: This cross-sectional study was performed in the first half of 2014. The sample size included 700 patients selected using multistage sampling. Firstly $30 \%$ of health centers were randomly selected as a cluster. Then, the patients were randomly selected from each cluster. The study data were collected through a questionnaire consisting of 2 parts - demographic variables and the rules of the referral system. Data were analyzed using descriptive statistics, Chi Square, and Logistic Regression.

Results: From 700 patients who received the level 2 services, $69 \%$ of cases were female and $31 \%$ were male. One hundred eighty-two cases (26\%) had referral form from health house. Only $56.4 \%$ of persons referred to the centers because of diagnosis of the family physician. For $34 \%$ of cases, the specialists wrote the results of their evaluation in feedback form. Four hundred sixty-three patients did not return to their family physician because of lack of knowledge.

Conclusion: The referral situation to level 2, in the present study was poor. Ease of access to specialized services level 2 , and educational intervention for healthcare staff and familiarizing people with the objectives of the family physician program and referral system are recommended.

Keywords: Referral system, Family physician, Healthcare
\end{abstract}

\section{Introduction}

The healthcare system is organized for higher effectiveness and efficiency and also in order to create equity and possibility of all people having access to three levels of healthcare and access of individuals to more specialized services through development of the referral system (1). Referral systems are relatively easy in terms of design, but implementing them is extremely difficult. Efficiency of a patient referral system's performance depends on the

\section{Corresponding author:}

Ehsan Movahed, School of Public Health, Shahid Sadoughi University of Medical Sciences, Yazd, Iran.

Tel: +98.9133908319, Fax:+98.3431325403, Email: ehsanmovahed89@yahoo.com

Received: October 06, 2016, Accepted: January 28, 2017, Published: April 2017

iThenticate screening: January 29, 2017, English editing: March 12, 2017, Quality control: April 14, 2017

(C) 2017 The Authors. This is an open access article under the terms of the Creative Commons Attribution-NonCommercialNoDerivs License, which permits use and distribution in any medium, provided the original work is properly cited, the use is non-commercial and no modifications or adaptations are made. 
different levels of the health system and ensuring them from staff, efficiency of the informing system performance, ease or difficulty of transport and the costs of different levels of care (2). In Turkish social insurance organizations, the family physician is the first person who visits the patient and provides the necessary examination and treatment, and if it is necessary, refers the patient to the second and third levels of services (3). In Iran, the National Plan of Family Physicians has been implemented according to article 91 of the Fourth Development Plan with the aim of strengthening the referral system, increasing the accountability in the health market, increasing the access to health services, reducing the unnecessary costs in the health market, and increasing the coverage of services in all rural areas and small cities with inhabitants less than 2000 people (4). Karimi suggests creating the health records for patients and also emphasizes on the necessity of free healthcare service for rural areas (5). In studying the patients in two Northern provinces of Iran in 2008, 46\% of them were referred to specialists according to the general physician diagnosis, while $56 \%$ were referred due to the patient's request. Among all patients referred to this level, only for $17 \%$ of them a copy of the list was sent to the health house. Despite several researches emphasizing on the importance and necessity of using an appropriate referral system; in Iran, evidence suggests that the quality of the existing referral system is not very good. For example, a study in the Northern provinces indicates that the quality of the referral system in $67 \%$ of cases were unfavorable (6). Other evidence suggests that only $25.3 \%$ of the cases were referred back to family physicians after receiving second level services (6). Nowadays, in many countries including North America, Western Europe and Canada, family physicians are responsible for healthcare delivery and a health team. In Britain, Canada, South Korea and Chile, the national health system is based on the level of the referral system and family physicians (7). Although an increase of accountability, people's access to healthcare and reduction of unnecessary costs are the objectives of the plan, some evidence suggests that the most significant weaknesses of the plan are the deficiency of the referral system and the lack of providing appropriate feedback from physicians who specialized into family physicians, lack of foresight facilities, and high volume of tasks (8). According to the patients, most of them do not revert to the first level due to lack of awareness and in general, the process of referring to a specialist physician through the Family Physician Program has not been observed (9, 10). Given the importance of the referral system in southern cities, in this study it was aimed to determine the function of the referral system in the Family Physician Program in Jiroft University of Medical Sciences.

\section{Material and Methods}

This study was a cross-sectional study which was conducted in 2014 on all cases who referred to the health centers of Jiroft University of Medical Sciences which was implementing the Family Physician Program. The sample size included 700 patients selected using multistage sampling. Firstly 30\% of health centers were randomly selected as a cluster. Then, the patients were randomly selected from each cluster. In the first stage, approximately 19 health centers $(30 \%)$ among all centers implementing the family physician project were selected as research cluster in each city. In order to select them, the name of the health centers implementing the Family Physician Program were listed. Systematic random sampling was used in the first three centers listed. Accordingly, 5 of the 15 centers that were covered by Jiroft city, 2 of the 6 centers covered by Anbar-Abad city, 3 centers of the 9 centers covered by south of Roodbar city, one of the three centers covered by Faryab city, 3 of the 10 centers covered by Kahnooj city, 2 of the 7 centers covered by Ghalehgang city, and 3 of the 8 centers covered by Manoojan city were selected, which in total, included 19 of the total 58 centers. In the second stage, the researcher referred to all healthcare centers, and recorded the names of all patients who had not recovered from illness at the first level and required a specialist physician at level 2, from the registered office or the list of referenced patients and interviews were done by visiting them at their homes and if they referred to level 2 and had received needed services, they also were studied. Inclusion criteria were patients' satisfaction to participate in the study, having medical records, referred to health centers and referral to Level 2 during the past month, covered by the Jiroft University of Medical Sciences. Exclusion criteria were patient dissatisfaction and lack of cooperation. Data collection tool was a standardized questionnaire that was designed in the Northern provinces by Pour Shirvani and colleagues (12). Score 1 assigned to the "Yes" answers and zero score was assigned to the "No" answers. The recorded data included: age, sex, occupation, place of residence, date of admission, the records in "Health House" referral system, the referral request, visiting date and type of service from Level 2, and feedback from specialist physicians at level 2. Results of the received services in health records, telephone follow-ups by family physicians and health workers and ultimately, patient satisfaction from referral process were collected through interviews, observation of rural insurance and related charts at the center for 5 to 7 patients. Results of answered questions were categorized using a scale of three Bugardos ratings at optimum level (with $75-100 \%$ of the total score), relatively favorable (75-50\% of the score), and poor (less than $50 \%$ of the total score) (13). Data were analyzed using descriptive statistics, Chi Square, and Logistic Regression, and $\mathrm{p}<0.05$ considered as significant. 


\section{Results}

There were $217(31 \%)$ males and 483 females (69\%) from 700 patients who referred and received the service at levels 1 and 2. Occupation of 436 cases $(62.3 \%)$ was housekeeping. Most age groups that participated in the study (46.4\%) were between 20 to 40 years. Table 1 shows the frequency distribution of demographic variables. Based on the data in Table 2, Chi square test showed that the percentage of people who have adhered to the referral system in patients referred from health centers $(72.6 \%)$ was significantly higher than patients without coordination with health centers $(50.7 \%)$ who referred to family physicians. In terms of sending referral transcript to the Health Houses, Chisquare test showed that among those that physicians had referred to Level $2(42.5 \%)$ and patients who were selfreferred to level $2(13.7 \%)$ had significant difference between the two groups $(\mathrm{p}=0.000)$. According to Table 2 , among 136 cases of feedback provided by the specialists of Level 2, 23 cases (5.7\%) has good quality, 22 cases $(5.6 \%)$ had relatively good quality, and 91 cases $(23 \%)$ had poor quality that it did not show significant differences between the referred patients $(\mathrm{p}=0.812)$. Table 2 reveals distribution of patients admitted to Level 2 in terms of "Health House" referral, sending a copy of the referral to home care, quality feedback, record the results in health records by the type of referral (by referral system, self-referral by patient). According to data from Table 3, among the patients who the family physician referred to the second level, 104 patients $(41.2 \%)$ noted lack of awareness as cause of lack of referral to the family physician that the situation in patients who they asked to select their own family physician showed significant differences $(\mathrm{p}=0.000)$. In terms of the satisfaction level, statistical analysis showed there was not a significant relationship between the level of patient satisfaction, the referral system, and referral system observance by them $(\mathrm{p}=0.073)$. Table 3 reveals distribution of patients admitted to Level 2 on the causes of visits to the family physician and the patient satisfaction referral system by the type of referral (by referral system, self-referral by patient). Results in Table 4 show that when a physician sends a copy of the referral health center, the possibility of asking patients for referrals from health centers exceeds 3.5 times rather than when the physician does not send a copy to the referral health center.

Table 1. Distribution of demographic variables

\begin{tabular}{|l|l|l|l|}
\hline Variable & Range & $\mathrm{n}$ & $\%$ \\
\hline Age (years) & $<20$ & 119 & 17 \\
\cline { 2 - 4 } & $20-40$ & 325 & 46.4 \\
\cline { 2 - 4 } & $40-60$ & 127 & 18.2 \\
\cline { 2 - 4 } & $>60$ & 129 & 18.4 \\
\hline \multirow{5}{*}{ Oender } & Male & 217 & 31 \\
\cline { 2 - 4 } & Female & 483 & 69 \\
\hline \multirow{5}{*}{ Education } & Housewife & 436 & 62.3 \\
\cline { 2 - 4 } & Employee & 13 & 1.9 \\
\cline { 2 - 4 } & Unemployed & 114 & 16.3 \\
\cline { 2 - 4 } & Unofficial education & 137 & 19.6 \\
\cline { 2 - 4 } & Illiterate & 142 & 20.3 \\
\cline { 2 - 4 } & Some high school & 108 & 15.4 \\
\cline { 2 - 4 } & High school diploma and above & 450 & 64.3 \\
\hline Total & - & 700 & 100 \\
\hline
\end{tabular}

Table 2. Distribution of patients admitted to Level 2 in terms of availability

\begin{tabular}{|c|c|c|c|c|c|c|c|}
\hline \multirow[t]{3}{*}{ Variable } & & \multicolumn{4}{|c|}{ Referral to the Health House by } & \multirow[t]{3}{*}{ Total } & \multirow[t]{3}{*}{$p$-value } \\
\hline & & \multicolumn{2}{|c|}{ Physician } & \multicolumn{2}{|c|}{ Patient } & & \\
\hline & & $\mathrm{n}$ & $\%$ & $\mathrm{n}$ & $\%$ & & \\
\hline \multirow[t]{2}{*}{ Referral from the Health House } & Yes & 132 & 72.6 & 50 & 27.4 & 182 & \multirow[t]{2}{*}{0.000} \\
\hline & No & 263 & 50.7 & 255 & 49.3 & 518 & \\
\hline \multirow[t]{2}{*}{ A copy of the referral to health center } & Yes & 168 & 42.5 & 42 & 13.7 & 210 & \multirow[t]{2}{*}{0.000} \\
\hline & No & 227 & 57.5 & 263 & 86.3 & 490 & \\
\hline \multirow[t]{4}{*}{ Quality of feedback } & No & 259 & 65.6 & 203 & 66.5 & 462 & \multirow[t]{4}{*}{0.812} \\
\hline & Weak & 91 & 23 & 63 & 20.7 & 154 & \\
\hline & Average & 22 & 5.6 & 21 & 6.8 & 43 & \\
\hline & Favorable & 23 & 5.7 & 18 & 6 & 41 & \\
\hline \multirow[t]{2}{*}{ Recording the results in health records } & Yes & 108 & 27.4 & 62 & 20.3 & 170 & \multirow[t]{2}{*}{0.019} \\
\hline & No & 287 & 72.6 & 243 & 79.7 & 530 & \\
\hline
\end{tabular}


http://www.ephysician.ir

Table 3. Distribution of patients admitted to Level 2 in terms of availability

\begin{tabular}{|c|c|c|c|c|c|c|c|}
\hline \multirow[t]{3}{*}{ Variable } & & \multicolumn{4}{|c|}{$\begin{array}{l}\text { Referral to the health house } \\
\text { by }\end{array}$} & \multirow[t]{3}{*}{ Total } & \multirow[t]{3}{*}{$\begin{array}{l}p- \\
\text { value }\end{array}$} \\
\hline & & \multicolumn{2}{|c|}{ Physician } & \multicolumn{2}{|c|}{ Patient } & & \\
\hline & & $\mathrm{n}$ & $\%$ & $\mathrm{n}$ & $\%$ & & \\
\hline \multirow[t]{5}{*}{$\begin{array}{l}\text { The causes of not using the Family } \\
\text { Physician }\end{array}$} & $\begin{array}{l}\text { Lack of } \\
\text { awareness }\end{array}$ & 104 & 41.2 & 77 & 34.4 & 177 & \multirow[t]{5}{*}{0.000} \\
\hline & Impatience & 57 & 22.6 & 30 & 14.1 & 87 & \\
\hline & Traffic problems & 73 & 29 & 60 & 28.5 & 133 & \\
\hline & Lack of time & 16 & 6.4 & 39 & 18.3 & 55 & \\
\hline & Other & 2 & 0.8 & 10 & 4.7 & 12 & \\
\hline \multirow[t]{5}{*}{ Levels of patient satisfaction } & Very low & 33 & 8.3 & 23 & 7.5 & 56 & \multirow[t]{5}{*}{0.073} \\
\hline & Low & 67 & 16.9 & 54 & 17.7 & 121 & \\
\hline & Average & 160 & 41 & 151 & 49.6 & 311 & \\
\hline & High & 97 & 24.2 & 51 & 16.7 & 148 & \\
\hline & Very high & 38 & 9.6 & 26 & 8.5 & 64 & \\
\hline
\end{tabular}

Table 4. Findings of Logistic Regression

\begin{tabular}{|l|l|l|l|l|l|l|}
\hline Variable & B & WALD & Sig. & EXP (B) & \multicolumn{2}{|l|}{ 95\% C.I. for XP (B) } \\
\cline { 5 - 8 } & & & & & LOWER & UPEER \\
\hline Copies of referral sent to health centers & 1.26 & 34.34 & 0.000 & 3.5 & 2.31 & 5.39 \\
\hline Advisory provided by family physicians & 0.408 & 5.43 & 0.020 & 1.5 & 1.06 & 2.12 \\
\hline Phone call by behvarz (health worker) & 0.796 & 14.84 & 0.000 & 2.21 & 1.47 & 3.32 \\
\hline Help of specialist physician to patient & 0.576 & 9.7 & 0.002 & 0.56 & 0.39 & 0.80 \\
\hline Education levels & 0.704 & 12.47 & 0.000 & 0.49 & 0.33 & 0.73 \\
\hline
\end{tabular}

\section{Discussion}

The direct referring of people to the health centers is contrary to the Universal Declaration of Alma-Ata and the objectives of Iran's Health Network system (12). But the available evidence suggests that about two-thirds of patients who were referred to Level 2, referred to health centers without a referral from the health center. It was also consistent with the studies of Poor Shirvani and colleagues (9), and Chaman and colleagues (13). The increase in direct patient referrals to family physicians is related to the lack of awareness of the benefits of the Family Physician Program $(14,15)$. Hassan Zadeh and colleagues, in their study, emphasized that implementing and managing an effective referral system requires the inclusive cooperation of the government, and carrying out sweeping reforms (16). The reported findings of feedback by physicians from Level 2 demonstrated that more than two-thirds of family physicians without referral patients had no feedback and less than $6 \%$ of them had favorable feedback. It seems the lack of supervision by the medical universities and insurance companies on the healthcare intensify to poor feedback from level two to level one. The important benefits of sending feedback to the family physicians are avoiding the unnecessary costs and fixing them with treatment and baseline levels of disease. In the family physician program and rural insurance in Kerman and Yasouj, increase of awareness of family physicians from feedback, results in reduction of unnecessary referrals to higher levels and accordingly, the reduced costs to the second level (17). On the other hand, with strict observance of the principles of the referral system by physicians and contributions of stakeholders in order to solve the existing problems, it can be helped to improve feedback from level two to level one (18). In the present study, results of visiting were appropriate in the health records of patients referred by family physicians than self-referential patients, but in general, the status or health records were not ideal. Cahman and colleagues also studied results of visiting and found that in only $12.8 \%$ it was recorded in health records (13). Lack of registration of results in the health records may be due to the paperwork, lack of systemic files, fatigue caused by activities, lack of time, a lot of people visiting the family physician, while in the study of Zahra Hafezi and colleagues, more than $95 \%$ of patients thought a referral system was effective and the main advantage of this program was constructing the profiles for the treatment of insured health records (19). Therefore, promoting the family physician's awareness about the mentioned issue is a suitable tool. According to findings reported in Table 3, unawareness and traffic problems are two main causes of lack of visits to the family physician after the Level 2 visit. It seems, serious consideration of healthcare providers and executives of plans is necessary to improve the provision of information to public authorities covered by its orientation with various aspects of the program. In this research, observing the referral system had little impact on patient satisfaction and in the study conducted by Poor Shirvani 
and colleagues, the patient satisfaction rate was reported as $66.6,51.3$, and $53.6 \%(9)$. The lack of proper observance of the referral system and the lack of tangible benefits of this system, time consuming, reducing drugs per prescription, and poor awareness of personnel from family medicine can be the reasons of dissatisfaction, because the level of satisfaction determines the level of performance. So that in the research of Zahra Hafezi. et al., the emphasis is on workshops and educational programs to promote and improve the performance of physicians in health and technical areas, and promoting the cooperation between the departments (19). Results in Table 4 show that when a physician sends a copy of the referral form to the health center, the possibility of asking patients for referrals from health centers exceeds 3.5 times rather than when the physician does not send a copy of the form to the referred health center. Therefore, the necessity of sending a copy by referring the patient to the health center is more than ever. Results of advice by the physician showed that when the physician advises patients, it is more likely to refer a patient request. It means that, with knowledge and patience in visiting patients and providing advice, it will be possible to convince more patients to compliance to the referral system. However, sometimes physicians have not cooperated in advising the patients, so that due to the views of 32 family physicians who participated in the study of Manca et al, the causes of lack of advising by the physicians are related to the overload of work, income inequality, lack of control over their paperwork and repeated phone calls (20). Hosseini and colleagues found out that the following-up and advice from the physician after a referral for asking the latest results of treatment was not observed in $12.2 \%$ while in $68 \%$ it was somewhat observed (21). If a behvarz (health worker) provides the recommendations for the patient, the possibility of a patients request for referring to the "Health House" is as much as 2.2 times more than when necessary recommendations have not been provided. Providing the recommendations by both the physician and the behvarz are necessary, health workers provide recommendations to reduce the times of the patient's visit to the family physician. Leibowitz et al, concluded that telephone counseling and the provision of medical advice can reduce workload and subsequent cost (22). In the case of selecting specialists by the patient, when the patient's family physician guides them to the specialists, the possibility of a patient's request for a referral as 0.44 is less than when the physician did not guide. Guidance and selection of specialist physicians leads to the correct treatment and reduced costs. Good results were also obtained about the education, which means when patients have higher education, then the possibility of asking patients for referrals is 0.55 and less. Therefore, as people have higher educational level, their visiting and referral to physician education is reduced. People, who are better educated, do the appropriate action. The limitation of this study is that we used a closed questionnaire and, as a result, some aspects might have been missed. Therefore, future studies are recommended to use individual or group interviews for achieving further viewpoints of the other stakeholders in the referral system.

\section{Conclusions}

According to the results, sending a copy of the referral, sending feedback, and recording the results were evaluated as undesirable. It seems that by providing electronic health files for the covered population, it will be possible to motivate and justify specialist physicians in the treatment of referred patients, considering economic problems and rights and benefits of other health team members as an effective approach to improve the referral system in the Family Physician Program. Additionally, by providing conditions for physicians and nurses in rural areas, availability in all hours of the day, and increasing the efficacy of this important national program, the quality of the referral system can be improved.

\section{Acknowledgments:}

This study is derived from the research project No. 93/32 (Adopted: 93/02/27; Deputy of Research and Technology, Kerman University of Medical Sciences). Hereby, we thank the deputy of Research and Technology (Kerman University of Medical Sciences) for financially supporting the study, and Mrs. Mahboubeh Ameri for her assistance.

\section{Conflict of Interest:}

There is no conflict of interest to be declared.

\section{Authors' contributions:}

All authors contributed to this project and article equally. All authors read and approved the final manuscript.

\section{References:}

1) Davoudi S. Introduction to health sector reform. Tehran: Asare Mouaser Pub; 2006: 233-7.

2) Panahi B. Operational process of the social security system. J Soc Secur. 2009; 1(1): 91-9.

3) Ferdosi M, Vatankhah S, Khalesi N, Ayoobian A. Designing a referral system management model for direct treatment in social security organization. J Mil Med. 2012; 14(2): 129-35. 
4) Physician Instruction F. Iran: Ministry of Health and Medical Education. Version. 2011; 12: 4-102.

5) Karimi S. Comparative Study of the Situation Villagers Access to Health Services in Selected Countries and Provide a Model for Iran, Ph.D Dissertation. Tehran: Azad Islamic Univercity of Science and Research Branch; 2007.

6) Raeisee P, Motlagh M, Kabir M. Evaluation of the performance of referral system in family physician program in Iran University of Medical Sciences: 2009. Hakim Research Journal. 2010; 13(1): 19-25.

7) Jolaee H, Alizadeh M, Falah Zadeh M, Baseri A, Sayyadi M. Assessment of clinical skills province of Family Physicians clinical test based on the observed (OSCE) Journal of Medical Education Developmalet Center. Strides Dev Med Educ. 2010; 7(2): 92-8.

8) Mohammadi Sh, Mohammadi Sh, Bahrami S, Amiri A, Shahri A. Knowledge and attitudes of health insurance executives and medical universities in the province Kurdistan \& Qazvin and dependent hospitals in implemmentation physician family plan. Advances in Natural and Applied Sciences. 2014; 8(7): 827-34.

9) Nasrollahpour Shirvani D, Ashrafian Amiri H, Motlagh ME, Kabir MJ, Maleki MR, Shabestani Monfared A, et al. Evaluation of the function of referral system in family physician program in Northern provinces of Iran: 2008. Journal of Babol University of Medical Sciences. 2010; 11(6): 46-52.

10) Motlagh E, Nasrollahpour Shirvani S, Ashrafian Amiri H, Kabir M, Shabestani Monfared A, Nahvijoy A. Satisfaction of family physicians (FPs) about effective factors on activation of FP program in medical universities. Journal of Guilan University of Medical Sciences. 2011; 19(76): 48-55.

11) Mirzaie K. Research, Researching \& Writing. Tehran: Jameheshenasan Publication; 2009.

12) Nasrollahpour Shirvani D, Ashrafian Amiri H, Kabir M, Shabestani Monfared A. To evaluate the quality of family physician program in Northern Provinces of Iran; 2008. Back to cited text. (22): 91-102.

13) Chaman R, Amiri M, Raei DM. The national family physician and the quality of referral system. 2012 : 785-90.

14) Alidoosti M, Tavassoli E, Delaram M, Najimi A, Sharifirad G. The relationship between satisfaction and knowledge about family-doctor program in Shahr-e-Kord. Zahedan Journal of Research in Medical Sciences. 2011; 13(6): 36-9.

15) Shams A, Mofid M, Rejlian F. Survey of referal system influenced factors from the perspective of referrings of Isfahan educatinal hospitals. Health Information Management. 2011; 7: 669-78.

16) Hasan Zadeh A. People share from medical expenses. Atiye Weekly. 2006; 510.

17) Khosravi S, Amiresmaeili M, Yazdi Feyzabadi V. Performance evaluation and insurance plans of rural family physicians: case study of kerman medical sciences university. Paper presented at: Proceedings of the Role of Family Physicians in Health Systems Congress. 2012: 13-4.

18) Raeesi P, Nasrollahpour Shirvani D, Kabir M. To evaluate the quality of family physician program in Iran University of Medical Sciences. Tehran. Reported Resesrch Project of Iran University of Medical Sciences. 2009; 792.

19) Hafezi Z, Asqari R, Momayezi M. Monitoring performance of family physicians in Yazd. Toloo-eBehdasht. 2009; 8: 16-25.

20) Manca DP, Varnhagen S, Brett-MacLean P, Allan GM, Szafran O, Ausford A, et all. Rewards and challenges of family practice Web-based survey using the Delphi method. Can Fam Physician. 2007; 53(2): 277-86.

21) H HF. Performance evaluation of family physician program in Imam Khomeini's Relief Committee Yazd province. Azad University. 2005; 24.

22) Leibowitz R, Day S, Dunt D. A systematic review of the effect of different models of after-hours primary medical care services on clinical outcome, medical workload, and patient and GP satisfaction. Fam Pract. 2003; 20(3): 311-7. doi: 10.1093/fampra/cmg313. PMID: 12738701. 